\title{
Hostile climates are barriers to diversifying the geosciences
}

\author{
Erika Marín-Spiotta ${ }^{1}$, Rebecca T. Barnes ${ }^{2}$, Asmeret Asefaw Berhe ${ }^{3}$, Meredith G. Hastings ${ }^{4}$, Allison Mattheis ${ }^{5}$, \\ Blair Schneider ${ }^{6}$, and Billy M. Williams ${ }^{7}$ \\ ${ }^{1}$ Department of Geography, University of Wisconsin-Madison, Madison, WI 53706, USA \\ ${ }^{2}$ Environmental Studies Program, Colorado College, Colorado Springs, CO 80903, USA \\ ${ }^{3}$ Department of Life and Environmental Sciences, University of California, Merced, CA 95343, USA \\ ${ }^{4}$ Department of Earth, Environmental and Planetary Sciences and Institute at Brown for Environment and Society, \\ Brown University, Providence, RI 02912, USA \\ ${ }^{5}$ Applied and Advanced Studies in Education, California State University Los Angeles, Los Angeles, CA 90032, USA \\ ${ }^{6}$ Kansas Geological Survey, Lawrence, KS 66047, USA \\ ${ }^{7}$ American Geophysical Union, Washington, DC 20009, USA
}

Correspondence: Erika Marín-Spiotta (marinspiotta@wisc.edu)

Received: 30 November 2019 - Revised: 8 June 2020 - Accepted: 26 June 2020 - Published: 28 July 2020

\begin{abstract}
The geosciences are one of the least diverse disciplines in the United States, despite the field's relevance to livelihoods and local and global economies. Bias, discrimination, and harassment present serious hurdles to diversifying the field. These behaviors persist due to historical structures of exclusion, severe power imbalances, unique challenges associated with geoscientist stereotypes, and a culture of impunity that tolerates exclusionary behaviors and marginalization of scholars from underserved groups. We summarize recent research on exclusionary behaviors that create hostile climates and contribute to persistent low retention of diverse groups in the geosciences and other science, technology, engineering, and mathematics (STEM) fields. We then discuss recent initiatives in the US by geoscience professional societies and organizations, including the National Science Foundation-supported ADVANCEGeo Partnership, to improve diversity, equity, and inclusion by improving workplace climate. Social networks and professional organizations can transform scientific culture through providing opportunities for mentorship and community building and counteracting professional isolation that can result from experiencing hostile behaviors, codifying ethical practice, and advocating for policy change. We conclude with a call for a reexamination of current institutional structures, processes, and practices for a transformational and equitable scientific enterprise. To be truly successful, cultural and behavioral changes need to be accompanied by reeducation about the historical political structures of academic institu-
\end{abstract}

tions to start conversations about the real change that has to happen for a transformational and equitable scientific enterprise.

\section{Introduction}

Geoscientists work on problems that affect the environment, economy, and people's livelihoods, including natural hazards, energy, climate, water, and food security. Despite their societal relevance to environmental challenges from local to global scales, the geosciences remain one of the least diverse workforces in the United States and other countries. In 2016, almost $90 \%$ of US citizen graduate students in the geosciences were white (Wilson, 2018). Black and African American, Hispanic and Latinx, and Asian graduate students are disproportionately underrepresented in the geosciences compared to other science fields (Wilson, 2018). Women make up $30 \%$ of the science, technology, engineering and mathematics (STEM) workforce; in the geoscience workforce, they make up only $24 \%$ (Gonzales, 2019) and hold $20 \%$ of geoscience faculty positions (a gain from $14 \%$ in 2006) (Wilson, 2017, 2019). Women are predominantly represented in the most insecure and lowest salaried levels, making up a little over $40 \%$ of US geoscience non-tenuretrack instructor and lecturer positions (Wilson, 2017). Black, Hispanic, American Indian, Alaska Native, and Asian Pacific Islander women together represent only $5 \%$ and $7 \%$ of 
US bachelor's degrees and tenure-track faculty, respectively, in the earth, atmospheric and ocean sciences (NSF, 2015). In the UK, the Earth, Marine and Environmental Science cost center for the Higher Education Statistical Agency reported 25 women out of a total of 350 professors (7\%) in 2006 (Burek and Higgs, 2007). Many efforts to increase diversity in STEM disciplines have focused on recruitment (Hill et al., 2010), following the popular "leaky pipeline" metaphor, which projects that the low representation of people of color and white women in higher-level professional positions can be solved by increasing the number of individuals from these groups in graduate programs and at entry-level positions.

The data show that recruitment efforts are not sufficient. At the current rate, it will take at least 50 years to achieve gender parity in the geosciences, despite almost $40 \%$ of US Bachelor's degrees going to women. The number of $\mathrm{PhD}$ degrees in the earth, oceanic and atmospheric sciences conferred in the US to students from underserved racial and ethnic groups has not shown any gains in the last 40 years (Bernard and Cooperdock, 2018).

The "leaky pipeline" metaphor fails to adequately capture the experiences of underserved scientists for several reasons. It assumes, erroneously, that there is only one pathway into a successful scientific career (Holmes et al., 2015). The metaphor also implies that the attrition of people of color and white women from STEM disciplines is a passive process when in reality, documented forms of bias, discrimination, harassment, and other exclusionary behaviors actively contribute to low retention in the academic workforce (Cortina et al., 2011; NASEM, 2018). Furthermore, by focusing on "patching up the holes", the leaky pipeline model deflects attention from structural problems in academic and scientific institutions. Holes that contribute to leaks of some groups but not others are seen as consequences of a pipeline failure whereas a more thorough historical investigation (see Burek and Higgs (2007) for a history of women in geology in the UK, for example) exposes institutional structures, policies, and cultures that contribute to the exclusion of multiple groups from the STEM workforce.

A growing body of scholarly work documents academic and research environments that produce workplaces hostile to people of color, white women, those who identify as transgender, genderqueer, or non-conforming, religious minorities, academics with disabilities, and foreign-born or international scholars (Atherton et al., 2016; Bonistall Postell, 2015; Davis et al., 2015; Niemann, 2012; Sian, 2017; Camacho and Lord, 2011). In the UK, $41 \%$ of university students experienced sexual misconduct from staff (National Union of Students and the 1752 Group, 2018) and in the US, 59\% of undergraduate women students experienced harassing behavior (Cantor et al., 2019). Sixty-two percent of staff in US higher education reported experiencing or witnessing bullying in the past 18 months (Hollis, 2015). The geosciences are no exception. A survey of the Earth Science Women's Network found that $51 \%$ of survey respondents had experienced sexual harassment during their careers (Archie and Laursen, 2013). In the planetary sciences and astronomy, women of color felt unsafe due to their gender and race (Clancy et al., 2017). A UK survey of lesbian, gay, bisexual, transgender, and queer (LGBTQ) scientists found that almost a third had considered leaving the physical sciences due to negative workplace experiences (Gibney, 2019).

Efforts to broaden participation in STEM are more likely to have long-term impacts if they address conditions that create hostile workplace climates. In this article, we describe existing barriers to the diversification of the geosciences academic workforce to place current data for the US in a historical context and propose strategies for moving forward. We highlight the role of social networks and professional organizations in leading cultural change and introduce the US National Science Foundation-funded ADVANCEGeo Partnership that seeks to transform workplace climate through a multi-tiered approach that includes workplace climate education, bystander intervention, and consideration of harassment, bullying, and discrimination under the ethical conduct of research.

\section{Research on bias and discrimination}

Below we briefly summarize research from the geosciences and other STEM disciplines to underscore that strategies to broadening participation foremost need to address the manifestation of systemic bias and discrimination. A primary focus on addressing gender bias, to the detriment of attention to race and ethnicity and other identities, likely explains current trends in representation in the geosciences.

Bias manifests across the academic hierarchy, affecting recruitment into early-career levels and leadership positions as well as access to economic and material resources and opportunities for advancement. When evaluating identical applications for lab manager positions, faculty from researchintensive universities in the US rated those with typically female names as less competent, despite no difference in qualifications (Moss-Racusin et al., 2012). Applicants with typically male names were offered greater salaries and more mentoring opportunities. An analysis of > 1200 recommendation letters for applicants to US geoscience postdoctoral fellowships revealed quantitative and qualitative differences based on the applicant's gender (Dutt et al., 2016). All referees, regardless of gender, wrote longer letters that highlighted more leadership qualities and ground-breaking contributions for male applicants. Another study revealed gender and racial bias by faculty evaluating postdoctoral candidates in physics and biology (Eaton et al., 2020). A survey of new principal investigators in the UK found gender disparities in starting salaries, start-up funding, and teaching and administrative loads (Acton et al., 2019). An analysis of allotment of telescope use at a European observatory found that ratings 
of user proposals differed by gender of the reviewer (Patat, 2016).

Observed differences in the representation of people of color and white women in more senior leadership positions in the geosciences are not solely an artifact of historical trends in recruitment. In an international study of coastal geoscience and engineering, women were underrepresented in prestigious roles, including journal editorial positions (VilaConcejo et al., 2018). Only $3.8 \%$ of invitation-only commentaries on earth and environmental research in the prestigious journal Nature were authored by women (Conley and Stadmark, 2012). In the geosciences, women receive fewer journal referee invitations (Lerback and Hanson, 2017). Racial and ethnic minoritized geoscientists are invited to give fewer talks at conferences (King et al., 2018; Ford et al., 2019). Bias has also been documented more broadly in scientific awards (Lincoln et al., 2012; Lunnemann et al., 2019) and named professorships (Treviño et al., 2015). Bias affects career advancement at all levels and perceptions of the effects of bias in the earth and space sciences varies with gender, as revealed by a recent global survey (Popp et al., 2019).

\section{Beyond bias: hostile climates}

Efforts to increase the representation of women in STEM, for example, have focused on implicit bias awareness training and outreach focused on getting young women interested at earlier ages. The problem is not that women are uninterested in science but that they are discouraged from pursuing STEM early on. Those who enroll in science degree programs often encounter hostile behaviors, in addition to other barriers (Aycock et al., 2019; Settles et al., 2016). Harassment, bullying, microaggressions, sexism, racism, homophobia, transphobia, etc., are prevalent in academia. Some of these behaviors are illegal in many countries and yet they continue to persist. Others are not prohibited by law, yet still cause significant harm to physical and mental health and career fulfillment.

Sexual harassment affects the retention, advancement, and promotion of especially, yet certainly not exclusively, women in science. More than $50 \%$ of women faculty report experiencing harassment from their peers, and $20 \%-50 \%$ of women students report being sexually harassed by faculty or staff (NASEM, 2018). Surveys from the UK (Gaind, 2018) and Australia (Phillips, 2017) report similar findings. Gender harassment, or gender-based hostility, aversion, and denigration, is particularly problematic because it is the most commonly experienced yet least identified and reported form of sexual harassment (NASEM, 2018).

Insults and disrespectful verbal and non-verbal interactions that demean persons from underserved groups or invalidate people's experiences because of their identity can cumulatively create hostile workplace climates (Sue, 2010). Researchers have documented the effects of gendered and racialized microaggressions on faculty and students in STEM
(Camacho and Lord, 2011; Barthelemy et al., 2016; Leath and Chavous, 2018; McGee, 2016; Yosso et al., 2009). Repeated experiences of microaggressions, which can occur daily, negatively affect emotional well-being and mental health as well as learning, engagement, and feeling a sense of belonging and can contribute to the loss of diversity from STEM (Cabay et al., 2018).

Cortina (2008) identified interpersonal mistreatment and organizational hostility as a manifestation of gender and racial bias. These behaviors further exclude racial and gender minoritized groups from certain aspects of work life. Escalations of hate and bias incidents and violence that reflect a resurgence of nationalistic ideological movements in many countries also contribute to hostile climates on university campuses (Equality and Human Rights Commission, 2019; Dutt, 2019; Mani, 2020).

\section{Beyond gender: intersectionality and disproportionate impact}

A historic focus on diversity as one dimensional, e.g., binary gender, by STEM recruitment efforts has contributed to the persistent exclusion of multiple groups from the geosciences and other STEM disciplines. Black women earned only $69 \mathrm{PhD}$ degrees in the earth, atmospheric and oceanic sciences from 1973 to 2016, compared to 163 by Black men and over 5324 by white women (Bernard, 2018). Native American women earned 20 degrees in the geosciences. White men earned $14246 \mathrm{PhD}$ degrees in the same fields.

Black feminist scholarship and critical race theory provide a useful lens to understand how persons at the intersection of multiple marginalized identities (e.g., gender, age, race, ethnicity, ability, socioeconomic status, religion, nationality or citizenship) are more likely than others to experience discrimination and exclusionary behaviors (Collins, 2015; Crenshaw, 1989, 1993; Yosso et al., 2009). Crenshaw (1993) first used the term "intersectionality" to describe how African American women were inadequately protected by non-discriminatory employment laws due to experiencing both racism and sexism. By focusing on unequal power distribution in society (Collins, 2015), intersectionality helps reframe problems of underrepresentation and inequitable experiences in STEM as functions of social injustice, not individual or collective identities or characteristics.

Research guided by an intersectional framework reveals disproportionate impacts of bias and hostile behaviors on groups already underserved in STEM that provide insights into current trends in representation. Sexual and racial harassment have interactive effects on psychological wellbeing and occupational outcomes (Buchanan et al., 2009; Benard, 2018). A survey of astronomy and planetary sciences revealed that $40 \%$ of women of color compared to $27 \%$ of white women felt unsafe in the workplace due to their gender; $28 \%$ of women of color felt unsafe due to their race (Clancy et al., 2017). Women of color represented only $5 \%$ 
of speakers whereas white women received $25 \%$ of speaking slots at one geoscience conference in Canada (King et al., 2018). Transgender and gender non-conforming physicists experienced greater hostility in their work environments than cisgender men, and LGBTQ physicists of color faced greater levels of discrimination than their white peers (Atherton et al., 2016). In an example from Western Europe, Avraamidou (2020) explored how the experiences of an immigrant physicist are shaped not only by gender but also by religion and the broader socio-political context in the region.

\section{Structural and cultural barriers contributing to low diversity in the geosciences}

Identifying structural and cultural barriers that contribute to documented bias and hostile climates and to the persistence of low diversity is key for enacting change. Many of these factors are ubiquitous to academic STEM environments, including historical legacies of exclusion, hierarchical power differentials, institutional tolerance for abusive behaviors, as well as assumptions about who is (and who is not) identified as a scientist. Some of these can manifest in unique ways in the earth sciences and related careers, through stereotypes of geoscientists as field scientists and challenges associated with training, research, and fieldwork outside the bounds of academic institutions. To remove these barriers, multiple strategies are needed with engagement from members of the community across all levels, especially those in leadership positions (e.g., St. John et al., 2016).

\subsection{Historical legacies of exclusion}

Actions to increase diversity, equity, and inclusion need to start with an examination of the historical roots of contemporary experiences of exclusion in academia and STEM specifically. For example, women scientists were excluded from field expeditions for centuries, and until the 1960s were not allowed on research ship vessels in the US and Western Europe (Bonatti and Crane, 2012). Over their history, academic institutions have excluded and sometimes continue to exclude segments of society from pursuing higher education and employment based on economic class, gender, race and ethnicity, religion and citizenship.

Western science has a problematic history of exploiting bodies of color for the accumulation of knowledge and wealth, given strong ties between scientific research and colonial enterprises (Wynn-Grant, 2019; Deb Roy, 2018; Raby, 2017). Many US universities are built on capital from the African slave trade (Harris, 2015). The public land-grant system of universities in the US was built on expropriated Indigenous land (Lee and Ahtone, 2020). These fraught relationships continue today as highlighted by continued controversies surrounding, for example, mineral and resource extraction of indigenous lands globally and militarized re- sponses to protests against the siting of astronomy observatories on sacred land in Hawai'i (Fox and Prescod-Weinstein, 2019). In recent years, US universities have been forced to reckon with their racist foundations in slavery and plantation economies in response to current political events and student activism (Cahan, 2020; Doerer, 2018). Racist segregationist policies implemented post World-War II slowed the diversification of academic institutions; their impact remains today (Minor, 2008).

The siloing of academic disciplines and isolation of STEM from the social sciences contribute to a lack of acknowledgment of the legacies of colonialism and white supremacy in the academic enterprise and their continued effect on the participation of diverse communities in science. The dominant narrative of educational materials across disciplines champions scientists who had racist theories about human evolution and society, for example, and erases the contributions of people of color and other minoritized groups (Yacovone, 2018). Growing recognition that continuing to ignore these histories perpetuates their harm (Wynn-Grant, 2019) fuels calls to redesign scientific education and include more diverse perspectives into curricula from early childhood into graduate training programs (e.g., Arathi, 2019; Prescod-Weinstein, 2015).

\subsection{Hierarchical power dynamics}

Harassment, bullying, discrimination, and other exclusionary behaviors are especially harmful in strongly hierarchical systems like academia, where large power differentials exist within a number of relationships among faculty, students, trainees, postdoctoral researchers, and staff. The common model of advisor-student or trainee relationship exhibited in laboratories and research groups worldwide is reminiscent of the Medieval master-apprenticeship tradition, with advisors controlling access to expert knowledge, specialized equipment, data, professional networks, career opportunities, and research funding. In the US STEM graduate education model, funneling student financial support through principal investigator grants renders it difficult to speak out against abuses of power (Moss, 2018). An international survey of $>6300$ graduate students found that half of those bullied during their Ph.D. training identified their supervisor as the source and more than half feared repercussions if they spoke out (Lauchlan, 2019).

Negative mentorship experiences have harmful effects on people's well-being and on the research enterprise. More than a third of graduate students surveyed internationally have sought help for mental health related to their $\mathrm{PhD}$ experience (Woolston, 2019). In another survey of $>2200$ graduate students in 26 countries, negative mentoring experiences were correlated with depression and anxiety (Evans et al., 2018). Populations marginalized in STEM, e.g., racial and ethnic minoritized groups, transgender people, also face increased risks of anxiety and depression. 
A report from the US National Academies of Sciences underscored the importance of intentional and inclusive mentoring for positive personal and professional growth (NASEM, 2019). The report recommends changes to institutional structures and cultures to better support commitments to effective mentorship and adoption of collective or group mentoring and mentoring networks (Montgomery and Page, 2019), which can help diffuse power imbalances in the more traditional one-to-one mentoring relationships, as well as more independent funding support for students and earlycareer researchers. In addition, universities need to destigmatize mental health and provide more support services.

\subsection{Culture of impunity}

A culture of impunity in academic STEM creates an environment of tolerance for abuses of power and hostile behaviors. Existing professional rewards systems and structures for career advancement, including the current tenure system in the US, can disincentivize time spent on fostering collaborative, positive workplaces, and good mentoring practices. This harms the overall community and doubly affects those from already minoritized groups who disproportionately shoulder the burden of performing more academic service and emotional labor (Guarino and Borden, 2017; June, 2015).

Current policies, procedures, and approaches are inadequate to reduce harassment, and similarly, other exclusionary and hostile behaviors (NASEM, 2018). Institutions need to increase transparency and accountability in their responses to complaints and commit to more comprehensive cultural change to improve workplace climate. A recent US analysis of $>300$ cases of sexual misconduct by faculty and university administrators found a wide range of sanctions, including many cases where none were imposed (Cantalupo and Kidder, 2019). Consequently, $>50 \%$ of the cases involving faculty analyzed by Cantalupo and Kidder (2018) were cases of serial harassment, often bridging decades and multiple institutions. The example of sexual harassment, which in the US is illegal, illustrates how other behaviors that also create hostile workplace environments but may not be considered unlawful are allowed to persist.

\subsection{What happens in the field, stays in the field}

Fieldwork is an integral component of education, research, and employment for many, but not all geoscientists. Field research experiences can be defining moments in people's careers, inspiring for many (Beltran et al., 2020), yet can also be discriminatory and unsafe (Pickrell, 2020).

Fieldwork can present unique challenges that introduce risk to personal and mental health and increased vulnerability to hostile behaviors, especially for those with underserved or marginalized identities (Gewin, 2015; Giles et al., 2020; John and Khan, 2018). Field research may entail physically exhausting workdays, unknown or unfamiliar risks, and haz- ards, isolation from support networks, exposure to harsh environmental conditions, and unfamiliar language or cultural norms. Compounding these challenges are blurred lines between work and personal lives that often accompanies shared living situations and Vegas Rules (i.e., what happens in the field, stays in the field). A survey of over 650 field scientists revealed that $64 \%$ of them had personally experienced sexual harassment and over $20 \%$ had been sexually assaulted in the field (Clancy et al., 2014). Those with negative field experiences also reported career stalling, lateral career moves, or leaving their line of work altogether (Nelson et al., 2017). Interactions with other people in the field can also create unsafe environments, for example through manifestations of racism, sexism, homophobia, and xenophobia.

Individuals who do not conform to the stereotype of the able-bodied, white, cis-gender male rugged field scientist can experience aggravated professional and social isolation in the geosciences (Pickrell, 2020). Those with visible or invisible disabilities can feel marginalized by a culture that emphasizes able-bodied-ness as a stereotype of a successful geoscientist (Atchison and Libarkin, 2016). LGBTQ, intersex and asexual scientists in the earth sciences and physical sciences reported less disclosure of their queer identity, reflecting heteronormative societal assumptions in fields with reduced gender diversity (Mattheis et al., 2019a; Yoder and Mattheis, 2016).

Recognition of both the challenges and potential of fieldwork is key for increasing diversity, equity, and inclusion in the geosciences. Field safety plans need to include consideration of hostile and exclusionary behaviors. Enforced codes of conduct, egalitarian practices in the distribution of labor and leadership committed to safety and inclusivity contribute to positive field experiences (Nelson et al., 2017). The International Association for Geoscience Diversity (IAGD) in the US and the UK has developed and tested curricula for accessible field experiences to counteract some of the stereotypes and barriers about ability in the geosciences (Carabajal et al., 2017). Expanding training programs that match diverse career options for geoscientists that do not rely on fieldwork is also important.

\section{Community-wide partnerships for advancing change}

Advancing the cultural and structural changes needed to reduce the prevalence and impact of biases and hostile behaviors in the geosciences will require addressing several critical and interwoven processes at the individual, community, institutional and societal levels. The sections above have provided some suggestions for counteracting a number of barriers that manifest in the geosciences. Here we focus on efforts at the community and societal levels to improve workplace climate by highlighting the role of peer-mentoring formal and informal networks and of scientific societies in building 
community and developing new policies and educational and research programs.

\subsection{Building community through peer-mentoring networks}

Experiences of discrimination, harassment and other exclusionary behaviors can lead to feelings of isolation and insecurity, especially for underrepresented groups who may lack access to effective mentorship and visible role models (Aycock et al., 2019; Rainey et al., 2018). Callahan et al. (2015) proposed that social capital theory provides a framework for guiding efforts to diversify the geosciences workforce by focusing on building relationships of trust. The success of professional and peer-mentoring networks is based on this community and trust building. In addition to increased access to information, resources, and opportunities for professional development and advocacy, a sense of belonging and connection afforded by mentoring networks is key for career satisfaction and success, especially for underserved groups (Croom et al., 2017; Mouw et al., 2018; Hernandez et al., 2018).

The number of formal and informal organizations and networks in the geosciences focused on serving underrepresented and historically excluded groups has grown significantly in the past several years. These include, the National Technical Association (NTA), National Association of Black Geoscientists (NABG), Geoscience Alliance (Broadening Participation of Native Americans in Geoscience), Earth Science Women's Network (ESWN), Association for Women Geoscientists (AWG), GeoLatinas (Latinas in Earth and Planetary Sciences), Society of Latinxs/Hispanics in Earth and Space Sciences (SOLESS), MPOWIR (Mentoring Physical Oceanography Women to Increase Retention), International Association for Geoscience Diversity (IAGD), African Association of Women in Geosciences, Society of Exploration Geophysics (SEG) Women's Network, Women in Earth \& Environmental Science Australasia (WOMEESA), Baltic Consortium on Promoting Gender Equality in Marine Research Organisations, and the Pride in Polar Science Network, among others. Other broader STEM organizations such as the Society for the Advancement of Chicanos and Native Americans in Science (SACNAS) and National Organization for Gay and Lesbian Scientists and Technical Professionals (NOGLSTP) have recently launched new initiatives to increase representation of geoscientists.

Networks can take multiple approaches to supporting their members, through a physical regional chapter model, like the Association for Women Geoscientists (AWG) (Schneider et al., 2018), to primarily online peer-mentoring communities, like the Earth Science Women's Network (ESWN) (Barnes et al., 2018). Some organizations were started directly through building community via social media, like GeoLatinas. While recognizing that an increased online presence raises exposure to targeted harassment and other hos- tility, social media can serve as a transformational platform for building community and sharing of resources and experiences beyond institutional, disciplinary and national boundaries (Montgomery, 2018; Britton et al., 2019). Social media is facilitating relationship building across organizations and networks especially among early-career geoscientists, who are leading actions for change in the discipline.

Opportunities and challenges for formal and informal organizations include ensuring diverse and inclusive leadership, reflective of their membership, as well as partnering with others for continued outreach to include those who may be isolated from existing professional networks. In addition to supporting affinity groups, most of the listed organizations serve the wider community through technical and leadership professional development as well as through influencing policy change of larger professional societies. While promoting resources to improve the social capital of individuals in their networks, these organizations recognize the clear need to affect cultural and institutional change in the discipline.

\subsection{Setting standards for the discipline: role of scientific societies}

Professional organizations have an important role to play in transforming the culture of science, consistent with their historical function in establishing professional standards (Favaro et al., 2016; Marín-Spiotta et al., 2016). Societies have an additional responsibility because many of the barriers to full participation of a diverse community of scientists are replicated in organizational leadership, distribution of society awards, and conference and meeting experiences (e.g., Settles and O'Connor, 2014). The American Geophysical Union (AGU), Geological Society of America (GSA), and European Geoscience Union (EGU), for example, have established committees to address equity, diversity, and inclusion and raise awareness through education and training.

In recent years, professional societies across disciplines have enacted new policies in response to high-profile cases of sexual harassment and recognition of its effect on gender diversity in STEM. The AGU adopted a new ethics policy that redefines harassment, bullying, and discrimination as scientific misconduct and includes a range of sanctions to reinforce desired cultural norms (Williams et al., 2017). In response to public pressure, the US National Academy of Sciences approved the expulsion of members for misconduct. Funding organizations like the National Science Foundation and the National Institutes of Health in the US and the Wellcome Trust in the UK have implemented procedures to curtail research support to those in violation of specific conduct policies. While it is early to evaluate the long-term impact of these actions, increased transparency from organizations to their members on actions taken, including revocation of a number of awards for violations, for example, indicate some change is already occuring. 
Policies from scientific societies and funding agencies need continued re-evaluation of their effectiveness to ensure, for example, that they do not overly rely on reporting and investigative processes of other institutions, notably universities (see Cantalupo and Kidder, 2018, 2019). A focus on sexual harassment alone of many organizational policies also risks failing to protect from other hostile behaviors. Greater efforts need to be implemented to address racism and the negative experiences of racial and ethnic minoritized groups at society events and in the workforce (Dutt, 2019).

Professional societies can leverage their influence on culture and policy change through partnerships. More than 100 scientific organizations, including AGU and GSA, formed the Societies Consortium for Addressing Harassment in STEMM in 2019 to share practices to reduce hostile workplace behaviors. These organizations have committed to routinely examine diversity and equity in society activities and events, e.g. meetings, publications, governance structures, and honors and awards. Regular reevaluation of existing policies and support of early-career members, such as the provision of legal advice through AGU's new Ethics and Equity Center, is key for long-term change.

\subsection{Transforming workplace climate through partnerships: example of ADVANCEGeo}

An example of a successful collaboration among organizations and networks is the ADVANCEGeo Partnership, funded in 2017 by a four-year grant from the US National Science Foundation ADVANCE program. The goals of ADVANCEGeo are to collect data on workplace experiences through climate surveys distributed to professional societies to inform existing and future initiatives; develop and test bystander intervention training programs with geosciencerelevant scenarios and that incorporate intersectionality; develop teaching modules that define harassment, bullying and discrimination as scientific misconduct; and create a sustainable model in partnership with scientific societies.

The ADVANCEGeo team has delivered $>50$ interactive workshops that teach bystander intervention skills and facilitate team discussions about improving workplace climate. The bystander intervention approach shows promise to be a more effective means for reducing the prevalence of sexual harassment and other types of hostile behaviors than more common legal compliance training (NASEM, 2018). ADVANCEGeo's training uses AGU's framework of defining harassment and bullying as scientific misconduct (MarínSpiotta, 2018). The project also curates an online collection of resources on cultivating safe and inclusive workplace climates.

Conceived to tackle the problem of sexual harassment in the geosciences, ADVANCEGeo quickly expanded to address other exclusionary behaviors that contribute to a hostile workplace climate. The broader focus centers the role of intersectionality, which is critical for addressing continued challenges in the geosciences. It also engages those who may not experience sexual or racial harassment, for example, but are very familiar with bullying or other intimidating behaviors. A continued challenge is engaging all members of the community, especially those who are less likely to recognize hostile behaviors in the first place, yet are often in positions of leadership and thus have a responsibility for enacting cultural change.

\section{Recommendations for more equitable and just geosciences}

We have summarized research on cultural and structural barriers to broaden participation in the geosciences and other STEM fields and identified a range of strategies to dismantle these barriers, including community building by informal and formal professional networks and scientific societies. Geoscientists need to interrogate stereotypes and assumptions about the discipline, in particular the role of fieldwork, and adopt strategies to overcome challenges to inclusivity, accessibility and safety. The marginalization of diverse experiences and perspectives from the geosciences has a detrimental effect on human well-being, individual career opportunities, and the production of knowledge and innovative problem-solving needed to address complex environmental problems, whose harm disproportionately affects communities worldwide who continue to be excluded from participating in science. The legacy of the colonial and exclusionary foundations of our scientific and educational institutions in today's academic culture, structures and practices needs to be acknowledged for effective interventions.

Efforts to diversify the geosciences and create more equitable workplaces for transformational research and education need to address not only bias but also discriminatory, exclusionary and violent behaviors, e.g., sexism, racism, ableism, hetero-sexism, harassment, bullying, etc., that create hostile environments. A framework of intersectionality, identifying the multiple individual, cultural, and structural dimensions that shape the geosciences as a field is key for broadening participation (Núñez et al., 2020). Geosciences education research tends to not include a focus on participant social identities, and when included they are often one-dimensional (Mattheis et al., 2019b). Without addressing the ways that social norms and oppressions affect certain groups of students and faculty disproportionately, educational interventions are unlikely to promote inclusion and diversity in the geosciences.

Professional societies have the ability and responsibility to significantly change policies and cultural expectations. This is illustrated in partnerships that embrace the power of community-driven networks. New policy and educational initiatives by geoscience societies need to be adopted by the broader community and by academic institutions and then consistently reexamined to ensure transformational change in 
equity and diversity. We need to focus beyond gender alone to rectify current trends in the discipline. Beyond the numbers, critical action is needed to bring justice and accountability to diversity initiatives (see López and Cesspooch, 2019), so that no individual is faced with having to endure a hostile workplace to pursue an education and career in the geosciences.

Data availability. No data sets were used in this article.

Author contributions. EMS conceptualized the manuscript and led the writing, all authors contributed to writing the original draft, and EMS, RTB, AAB and MGH revised the final manuscript.

Competing interests. All authors are co-principal investigators on National Science Foundation awards that fund the ADVANCEGeo Partnership research and work (https://serc.carleton.edu/ advancegeo, last access: 26 July 2020). Erika Marín-Spiotta and Meredith G. Hastings are on the Leadership Council of the Earth Science Women's Network. Rebecca T. Barnes and Asmeret Asefaw Berhe are past leadership of the Earth Science Women's Network and Blair Schneider is past leadership of the Association for Women Geoscientists.

Special issue statement. This article is part of the special issue "Diversity and equality in the geosciences (EGU2019 EOS6.1 \& US4, AGU2018 ED41B, JpGU2019 U-02)". It is a result of the EGU General Assembly 2019, Vienna, Austria, 7-12 April 2019.

Acknowledgements. This work was supported by US National Science Foundation ADVANCE Partnership Awards Human Resources Division 1725879, 1726021, 1725650, 1726163, and 1725424. This manuscript is adapted from ADVANCEGeo workshop materials and a talk delivered at a Union Session at the 2019 European Geosciences Union General Assembly co-sponsored by the European Geosciences Union, the American Geophysical Union, and the Japanese Geoscience Union. Erika Marín-Spiotta acknowledges additional support from a Feminist Scholars Fellowship from the Center for Research on Gender and Women at the University of Wisconsin-Madison. We thank reviewers for their constructive feedback. For an updated list of identity-based organizations in the earth, environmental and space sciences see: https://eswnonline.org/ it-takes-a-village/org_network_list/ (last access: 26 July 2020).

Financial support. This research has been supported by US National Science Foundation ADVANCE Partnership Human Resources Division Awards 1725879, 1726021, 1725650, 1726163, and 1725424 .

Review statement. This paper was edited by Chiaki Oguchi and reviewed by two anonymous referees.

\section{References}

Acton, S. E., Bell, A. J., Toseland, C. P., and Twelvetrees, A.: A survey of new PIs in the UK, Elife, 8, https://doi.org/10.7554/eLife.46827, 2019.

Arathi: Race, Empire and Education, available at: https://medium.com/@arathings/ reading-list-race-empire-and-education-9da2b3cedc62, last access: 30 November 2019.

Archie, T. and Laursen, S.: Summative report on the Earth Science Women's Network (ESWN) NSF ADVANCE PAID Award (2009-2013), Ethnography and Evaluation Research, University of Colorado, Boulder, Boulder, CO, 149 pp., 2013.

Atchison, C. L. and Libarkin, J. C.: Professionally held perceptions about the accessibility of the geosciences, Geosphere, 12, 11541165, https://doi.org/10.1130/ges01264.1, 2016.

Atherton, T. J., Barthelemy, R. S., Deconinck, W., Falk, M. L., Garmon, S., Long, E., Plisch, M., Simmons, E. H., and Reeves, K.: LGBT Climate in physics: Building an inclusive community, American Physical Society, College Park, MD, 2016.

Avraamidou, L.: "I am a young immigrant woman doing physics and on top of that I am Muslim": Identities, intersections, and negotiations, J. Res. Sci. Teach., 57, 311-341, https://doi.org/10.1002/tea.21593, 2020.

Aycock, L. M., Hazari, Z., Brewe, E., Clancy, K. B. H., Hodapp, T., and Goertzen, R. M.: Sexual harassment reported by undergraduate female physicists, Phys. Rev. Phys. Educ. Res., 15, 010121, https://doi.org/10.1103/PhysRevPhysEducRes.15.010121, 2019.

Barnes, R. T., Marín-Spiotta, E., and Morris, A. R.: Building community to advance women in the geosciences through the Earth Science Women's Network, in: Women and Geology: Who Are We, Where Have We Come From, and Where Are We Going?, edited by: Johnson, B. A., Memoir, Geological Society of America, Denver, CO, 121-128, 2018.

Barthelemy, R. S., McCormick, M., and Henderson, C.: Gender discrimination in physics and astronomy: Graduate student experiences of sexism and gender microaggressions, Phys. Rev. Phys. Educ. Res., 12, 020119, https://doi.org/10.1103/PhysRevPhysEducRes.12.020119, 2016.

Beltran, R. S., Marnocha, E., Race, A., Croll, D. A., Dayton, G. H., and Zavaleta, E. S.: Field courses narrow demographic achievement gaps in ecology and evolutionary biology, Ecol. Evol., 10, 5184-5196, https://doi.org/10.1002/ece3.6300, 2020.

Bernard, R. E.: Diversity Data, available at: https://www. rachel-bernard.com/diversity (last access: 26 July 2020), 2018.

Bernard, R. E. and Cooperdock, E. H. G.: No progress on diversity in 40 years, Nat. Geosci., 11, 292-295, https://doi.org/10.1038/s41561-018-0116-6, 2018.

Bonatti, E. and Crane, K.: Oceanography and Women: Early Challenges, Oceanography, 25, 32-39, 2012.

Bonistall Postell, E. J.: International graduate students' risk and vulnerability to sexual violence and victimization, $\mathrm{PhD}$ Thesis, Department of Sociology and Criminal Justice, University of Delaware, Delaware, available at: http://udspace.udel.edu/ handle/19716/17041 (last access: 26 July 2020), 2015.

Britton, B., Jackson, C., and Wade, J.: The reward and risk of social media for academics, Nat. Rev. Chem., 3, 459-461, https://doi.org/10.1038/s41570-019-0121-3, 2019. 
Buchanan, N. T., Bergman, M. E., Bruce, T. A., Woods, K. C., and Lichty, L. L.: Unique and joint effects of sexual and racial harassment on college students' well-being, Basic Appl. Social Psychol., 31, 267-285, https://doi.org/10.1080/01973530903058532, 2009.

Burek, C. V. and Higgs, B.: The role of women in the history and development of geology: in introduction, Special Publications 281, Geological Society, London, 1-8, https://doi.org/10.1144/sp281.1, 2007.

Cabay, M., Bernstein, B. L., Rivers, M., and Fabert, N.: Chilly climates, balancing acts, and shifting pathways: What happens to women in STEM doctoral programs, Social Sci., 7, 23, 2018.

Cahan, E.: Amid protests against racism, scientists move to strip offensive names from journals, prizes and more, Science, https://doi.org/10.1126/science.abd6441, 2020.

Callahan, C. N., Libarkin, J. C., McCallum, C. M., and Atchison, C. L.: Using the lens of social capital to understand diversity in the earth system sciences workforce, J. Geosci. Educ., 63, 98-104, https://doi.org/10.5408/15-083.1, 2015.

Camacho, M. M. and Lord, S. M.: Microaggressions in engineering education: Climate for Asian, Latina and White women, in: 41st ASEE/IEEE Frontiers in Education Conference, Rapid City, SD, 2011.

Cantalupo, N. C. and Kidder, W. C.: A Systematic look at a serial problem: Sexual harassment of students by university faculty, Utah Law Rev., 2018, 671-786, 2018.

Cantalupo, N. C. and Kidder, W. C.: Systematic prevention of a serial problem: Sexual harassment and bridging core concepts of Bakke in the \#MeToo era, UC Davis Law Review, 52, 23492405, 2019.

Cantor, D., Fisher, B. S., Chibnall, S., Harps, S., Townsend, R., Thomas, G., Lee, H., Kranz, V., Herbison, R., and Madden, K.: Report on the AAU Campus Climate Survey on Sexual Assault and Misconduct, The Association of American Universities, Westat, Rockville, Maryland, 433 pp., 2019.

Carabajal, I. G., Marshall, A. M., and Atchison, C. L.: A Synthesis of instructional strategies in geoscience education literature that address barriers to inclusion for students with disabilities, J. Geosci. Educ., 65, 531-541, https://doi.org/10.5408/16-211.1, 2017.

Clancy, K. B. H., Nelson, R. G., Rutherford, J. N., and Hinde, K.: Survey of academic field experiences (SAFE): trainees report harassment and assault, PLoS One, 9, e102172, https://doi.org/10.1371/journal.pone.0102172, 2014.

Clancy, K. B. H., Lee, K. M. N., Rodgers, E. M., and Richey, C.: Double jeopardy in astronomy and planetary science: Women of color face greater risks of gendered and racial harassment, J. Geophys. Res.-Planets, 122, 1610-1623, https://doi.org/10.1002/2017je005256, 2017.

Collins, P. H.: Intersectionality's definitional dilemmas, Annu. Rev. Sociol., 41, 1-20, https://doi.org/10.1146/annurev-soc-073014$112142,2015$.

Conley, D. and Stadmark, J.: A call to commission more women writers, Nature, 488, 590, https://doi.org/10.1038/488590a, 2012.

Cortina, L. M.: Unseen injustice - incivility as modern discrimination in organizations, Acad. Manage., 33, 55-75, 2008.

Cortina, L. M., Kabat-Farr, D., Leskinen, E. A., Huerta, M., and Magley, V. J.: Selective incivility as modern discrimination in organizations: Evidence and impact, J. Manage., 39, 1579-1605, https://doi.org/10.1177/0149206311418835, 2011.

Crenshaw, K.: Demarginalizing the intersection of race and sex: A Black feminist critique of antidiscrimination doctrine, feminist theory and antiracist policies, University of Chicago Legal Forum 1989, University of Chicago, Chicago, 139-167, 1989.

Crenshaw, K.: Mapping the margins: Intersectionality, identity politics, and violence against women of color, Stanford Law Rev., 43, 1241-1299, https://doi.org/10.2307/1229039, 1993.

Croom, N. N., Beatty, C. C., Acker, L. D., and Butler, M.: Exploring undergraduate Black womyn's motivations for engaging in "sister circle" organizations, J. Women Hig. Educ., 10, 216-228, https://doi.org/10.1080/19407882.2017.1328694, 2017.

Davis, M. E., Vakalahi, H. F. O., and Scales, R.: Women of color in the academy, in: Disrupting the Culture of Silence: Confronting Gender Inequality and Making Change in Higher Education, edited by: De Welde, K. and Stepnick, A., Stylus Publishing, Sterling, Virginia, 265-277, 2015.

Deb Roy, R.: Decolonise science - time to end another imperial era, The Conversation, available at: https://theconversation.com/ decolonise-science-time-to-end-another-imperial-era-89189, last access: 5 April 2018.

Doerer, K.: How colleges confront their racist pasts, The Chronicle of Higher Education, available at: https://www.chronicle. com/article/how-colleges-confront-their-racist-pasts/, last access: 23 September 2018.

Dutt, K.: Race and racism in the geosciences, Nat. Geosci., 13, 2-3, 2020.

Dutt, K., Pfaff, D. L., Bernstein, A. F., Dillard, J. S., and Block, C. J.: Gender differences in recommendation letters for postdoctoral fellowships in geoscience, Nat. Geosci., 9, 805-808, https://doi.org/10.1038/ngeo2819, 2016.

Eaton, A. A., Saunders, J. F., Jacobson, R. K., and West, K.: How gender and race stereotypes impact the advancement of scholars in STEM: Professors' biased evaluations of physics and biology post-doctoral candidates, Sex Roles, 82, 127-141, 2020.

Equality and Human Rights Commission: Racial Harassment Inquiry: Survey of University Students, available at: https: //www.equalityhumanrights.com/en/publication-download/ racial-harassment-inquiry-survey-universities (last access: 26 July 2020), 2019.

Evans, T. M., Bira, L., Gastelum, J. B., Weiss, L. T., and Vanderford, N. L.: Evidence for a mental health crisis in graduate education, Nat. Biotechnol., 36, 282-284, https://doi.org/10.1038/nbt.4089, 2018.

Favaro, B., Oester, S., Cigliano, J. A., Cornick, L. A., Hind, E. J., Parsons, E. C. M., and Woodbury, T. J.: Your science conference should have a code of conduct, Front. Mar. Sci., 3, 103, https://doi.org/10.3389/fmars.2016.00103, 2016.

Ford, H. L., Brick, C., Azmitia, M., Blaufuss, K., and Dekens, P.: Women from some minorities get too few talks, Nature, 576, 32 35, 2019.

Fox, K. and Prescod-Weinstein, C.: The Fight for Mauna Kea is a fight against colonial science, The Nation, available at: https: //www.thenation.com/article/mauna-kea-tmt-colonial-science, last access: 24 July 2019.

Gaind, N.: UK survey reveals widespread sexual misconduct by academic staff, Nature, https://doi.org/10.1038/d41586-01804212-2, 2018. 
Gewin, V.: Indecent advances, Nature, 519, 251-253, https://doi.org/10.1038/nj7542-251a, 2015.

Gibney, E.: Discrimination drives LGBT+ scientists to think about quitting, Nature, 571, 16-17, 2019.

Giles, S., Jackson, C., and Stephen, N.: Barriers to fieldwork in undergraduate geoscience degrees, Nat. Rev. Earth Environ., 1, 7778, https://doi.org/10.1038/s43017-020-0022-5, 2020.

Gonzales, L.: Participation of women in the geoscience profession, Geoscience Currents Data Brief 15, American Geosciences Institute, 1-2, 2019.

Guarino, C. M. and Borden, V. M. H.: Faculty service loads and gender: Are women taking care of the academic family?, Res. High. Educ., 58, 672-694, https://doi.org/10.1007/s11162-0179454-2, 2017.

Harris, L. M.: Shades of segregated past in today's campus troubles, The Conversation, available at: https://theconversation.com/ shades-of-segregated-past-in-todays-campus-troubles-38818, (last access: 26 July 2020), 2015.

Hernandez, P. R., Bloodhart, B., Adams, A. S., Barnes, R. T., Burt, M., Clinton, S. M., Du, W., Godfrey, E., Henderson, H., Pollack, I. B., and Fischer, E. V.: Role modeling is a viable retention strategy for undergraduate women in the geosciences, Geosphere, 14, 2585-2593, https://doi.org/10.1130/ges01659.1, 2018.

Hill, C., Corbett, C., and St. Rose, A.: Why so few? Women in Science, Technology, Engineering and Mathematics, American Association of University Women, Washington, D.C., 134 pp., 2010.

Hollis, L. P.: Bully University? The Cost of Workplace Bullying and Employee Disengagement in American Higher Education, SAGE Open, 5, 2158244015589997 , https://doi.org/10.1177/2158244015589997, 2015.

Holmes, M. A., O'Connell, S., and Dutt, K.: Women in the Geosciences: Practical, Positive Practices Toward Parity, John Whiley, Hoboken, NJ, 2015.

John, C. M. and Khan, S. B.: Mental health in the field, Nat. Geosci., 11, 618-620, https://doi.org/10.1038/s41561-018-0219-0, 2018.

June, A. W.: The Invisible labor of minority professors, The Chronicle of Higher Education, available at: https://www.chronicle. com/article/the-invisible-labor-of-minority-professors (last access: 26 July 2020), 2015.

King, L., MacKenzie, L., Tadaki, M., Cannon, S., McFarlane, K., Reid, D., Koppes, M., and Kellett, D.: Diversity in geoscience: Participation, behaviour, and the division of scientific labour at a Canadian geoscience conference, Facets, 3, 415-440, https://doi.org/10.1139/facets-2017-0111, 2018.

Lauchlan, E.: Nature PhD Survey 2019 Report, Shift Learning, London, 38 pp., 2019.

Leath, S. and Chavous, T.: Black women's experiences of campus racial climate and stigma at predominantly white institutions: Insights from a comparative and within-group approach for STEM and non-STEM majors, J. Negro Educ., 87, 125-139, 2018.

Lee, R. and Ahtone, T.; Land-grab universities: Expropriated Indigenous land is the foundation of the land-grant university, High Country News, available at: https://www.hcn.org/issues/52.4/ indigenous-affairs-education-land-grab-universities, last access: 30 March 2020.

Lerback, J. and Hanson, B.: Journals invite too few women to referee, Nature, 541, 455-457, https://doi.org/10.1038/541455a, 2017.
Lincoln, A. E., Pincus, S., Koster, J. B., and Leboy, P. S.: The Matilda effect in science: Awards and prizes in the US, 1990s and 2000s, Social Stud. Sci., 42, 307-320, https://doi.org/10.1177/0306312711435830, 2012.

López, R. D., and Cesspooch, A.: Laying proper foundations for diversity in the geosciences, EOS, 100, https://doi.org/10.1029/2019EO137360, 2019.

Lunnemann, P., Jensen, M. H., and Jauffred, L.: Gender bias in Nobel prizes, Palgrave Commun., 5, 46, https://doi.org/10.1057/s41599-019-0256-3, 2019.

Mani, B.V.: Fighting the shadow pandemic, Inside Higher Ed, available at: https://www.insidehighered.com/views/2020/05/14/inclusiveteaching-needed-help-combat-xenophobia-racism-and, last access: 14 May 2020.

Marín-Spiotta, E.: Harassment should count as scientific misconduct, Nature, 557, 141, 2018.

Marín-Spiotta, E., Schneider, B., and Holmes, M. A.: Steps to building a no-tolerance culture for sexual harassment, EOS, 97, https://doi.org/10.1029/2016EO044859, 2016.

Mattheis, A., De Arellano, D. C., and Yoder, J. B.: A Model of queer STEM identity in the workplace, J. Homosex, https://doi.org/10.1080/00918369.2019.1610632, 2019a.

Mattheis, A., Murphy, M., and Marin-Spiotta, E.: Examining intersectionality and inclusivity in geosciences education research: A synthesis of the literature 2008-2018, J. Geosci. Educ., 67, 505517, https://doi.org/10.1080/10899995.2019.1656522, 2019 b.

McGee, E. O.: Devalued Black and Latino racial identities: A byproduct of STEM college culture?, Am. Educ. Res. J., 53, 16261662, https://doi.org/10.3102/0002831216676572, 2016.

Minor, J. T.: Segregation residual in higher education: A tale of two states, Am. Educ. Res. J., 45, 861-885, 2008.

Montgomery, B. L.: Building and sustaining diverse functioning networks using social media and digital platforms to improve diversity and inclusivity, Front. Digit. Human., 5, 22, https://doi.org/10.3389/fdigh.2018.00022, 2018.

Montgomery, B. L. and Page, S. C.: Mentoring beyond hierarchies: Multi-mentor systems and models, Commissioned for Committee on Effective Mentoring in STEMM, National Academy of Sciences, Engineering, and Medicine, 25 pp., available at: https://www.nap.edu/resource/25568/ Montgomeryandage-Mentoring.pdf (last access: 26 July 2020), 2019.

Moss, S.: Research is set up for bullies to thrive, Nature, 560, 529, https://doi.org/10.1038/d41586-018-06040-w, 2018.

Moss-Racusin, C. A., Dovidio, J. F., Brescoll, V. L., Graham, M. J., and Handelsman, J.: Science faculty's subtle gender biases favor male students, P. Natl. Acad. Sci. USA, 109, 16474, https://doi.org/10.1073/pnas.1211286109, 2012.

Mouw, C., Clem, S., Legg, S., and Stockard, J.: Meeting mentoring needs in physical oceanography: An evaluation of the impact of MPOWIR, Oceanography, 31, 171-179, https://doi.org/10.5670/oceanog.2018.405, 2018.

NASEM: National Academies of Sciences, Engineering, and Medicine: Sexual Harassment of Women: Climate, Culture, and Consequences in Academic Sciences, Engineering, and Medicine, The National Academies Press, Washington, D.C., https://doi.org/10.17226/24994, 2018. 
NASEM: National Academies of Sciences, Engineering, and Medicine: The Science of Effective Mentorship in STEMM, 978-0-309-49729-9, The National Academies Press, Washington, D.C., https://doi.org/10.17226/25568, 2019.

National Union of Students and The 1752 Group: Power in the Academy: Staff Sexual Misconduct in UK Higher Education, London, 55 pp., 2018.

Nelson, R. G., Rutherford, J. N., Hinde, K., and Clancy, K. B. H.: Signaling safety: Characterizing fieldwork experiences and their implications for career trajectories, Am. Anthropol., 119, 710722, https://doi.org/10.1111/aman.12929, 2017.

Niemann, Y. F.: Lessons from the experiences of women of color working in academia, in: Presumed Incompetent: The intersections of Race and Class for Women in Academia, edited by: Gutierrez y Muhs, G., Niemann, Y. F., Gonzalez, C. G., and Harris, A. P., University Press of Colorado, Utah State University Press, Boulder, CO, 446-499, 2012.

NSF: National Science Foundation. Women, minorities, and persons with disabilities in science and engineering, National Center for Science and Engineering Statistics, Washington, D.C., 2015.

Núñez, A.-M., Rivera, J., and Hallmark, T.: Applying an intersectionality lens to expand equity in the geosciences, J. Geosci. Educ., 68, 97-114, https://doi.org/10.1080/10899995.2019.1675131, 2020.

Patat, F.: Gender systematics in telescope time allocation at ESO, arXiV API, physics.soc-ph, 2016.

Phillips, N.: Australian students report high rates of sexual harassment and assault, Nature, https://doi.org/10.1038/nature.2017.22397, 2017.

Pickrell, J.: Scientists push against barriers to diversity in the field sciences, Science, https://doi.org/10.1126/science.caredit.abb6887, 2020.

Popp, A. L., Lutz, S. R., Khatami, S., van Emmerik, T. H. M., and Knoben, W. J. M.: A Global survey on the perceptions and impacts of gender inequality in the earth and space sciences, Earth Space Sci., 6, 1460-1468, https://doi.org/10.1029/2019EA000706, 2019.

Prescod-Weinstein, C.: Decolonising science reading list, available at: https://medium.com/@chanda/ decolonising-science-reading-list-339fb773d51f (last access: 30 November 2019), 2015.

Raby, M.: American Tropics: The Caribbean Roots of Biodiversity Science, University of North Carolina Press, Chapel Hill, NC, USA, 319 pp., 2017.

Rainey, K., Dancy, M., Mickelson, R., Stearns, E., and Moller, S.: Race and gender differences in how sense of belonging influences decisions to major in STEM, Int. J. STEM Educ., 5, 10, https://doi.org/10.1186/s40594-018-0115-6, 2018.

Schneider, B. B., Tranel, L., and Cremeans, M.: The Association for Women Geoscientists: 40 Years of Successes, Struggles, and Sisterhood, in: Women and Geology: Who Are We, Where Have We Come From, and Where Are We Going?, edited by: Johnson, B., The Geological Society of America, Denver, CO, 2018.

Settles, I. H. and O'Connor, R. C.: Incivility at academic Conferences: Gender differences and the mediating role of climate, Sex Roles, 71, 71-82, https://doi.org/10.1007/s11199-014-0355y, 2014.
Settles, I. H., O'Connor, R. C., and Yap, S. C. Y.: Climate perceptions and identity interference among undergraduate women in STEM, Psychol. Women Quart., 40, 488-503, https://doi.org/10.1177/0361684316655806, 2016.

Sian, K.: Being Black in a White World: Understanding Racism in British Universities. Papeles del Centro de Estudios sobre la Identidad Colectiva, International Journal on Collective Identity Research 176, ISSN 1695-6494, https://doi.org/10.1387/pceic.17625, 2017.

St. John, K., Riggs, E., and Mogk, D.: Sexual harassment in the sciences: A Call to geoscience faculty and researchers to respond, J. Geosci. Educ., 64, 255-257, https://doi.org/10.5408/1089-999564.4.255, 2016.

Sue, D. W.: Microaggressions in everyday life: Race, gender, and sexual orientation, John Wiley \& Sons, Hoboken, NJ, 2010.

Treviño, L. J., Gomez-Mejia, L. R., Balkin, D. B., and Mixon, F. G.: Meritocracies or masculinities? The Differential allocation of named professorships by gender in the academy, J. Manage., 44, 972-1000, https://doi.org/10.1177/0149206315599216, 2015.

Vila-Concejo, A., Gallop, S. L., Hamylton, S. M., Esteves, L. S., Bryan, K. R., Delgado-Fernandez, I., Guisado-Pintado, E., Joshi, S., da Silva, G. M., Ruiz de Alegria-Arzaburu, A., Power, H. E., Senechal, N., and Splinter, K.: Steps to improve gender diversity in coastal geoscience and engineering, Palgrave Commun., 4, 103, https://doi.org/10.1057/s41599-018-0154-0, 2018.

Williams, B. M., McEntee, C., Hanson, B., and Townsend, R.: The Role for a large scientific society in addressing harassment and work climate issues, Ann. Geophys., 60, 7, https://doi.org/10.4401/ag-7441, 2017.

Wilson, C. E.: Female geoscience faculty representation grew steadily from 2006-2016, Geoscience Currents 119, American Geosciences Institute, 2017.

Wilson, C. E.: Race and Ethnicity of U.S. Citizen Geoscience Graduate Students and Postdoctoral Appointees, 2016, Geoscience Currents 132, American Geosciences Institute, 2018.

Wilson, C. E.: Percentage of female faculty working within geoscience research fields, Geoscience Currents 136, American Geosciences Institute, 2019.

Woolston, C.: PhDs: the tortuous truth, Nature, 575, 403-406, 2019.

Wynn-Grant, R.: On reporting scientific and racial history, Science, 365, 1256-1257, https://doi.org/10.1126/science.aay2459, 2019.

Yacovone, D.: How scholars sustained white supremacy, The Chronicle of Higher Education, available at: https://www. chronicle.com/article/How-Scholars-Sustained-White/243053 (last access: 26 July 2020), 2018.

Yoder, J. B. and Mattheis, A.: Queer in STEM: Workplace experiences reported in a national survey of LGBTQA individuals in science, technology, engineering, and mathematics careers, J. Homosex, 63, 1-27, https://doi.org/10.1080/00918369.2015.1078632, 2016.

Yosso, T., Smith, W., Ceja, M., and Solórzano, D.: Critical race theory, racial microaggressions, and campus racial climate for Latina/o undergraduates, Harvard Educ. Rev., 79, 659-691, https://doi.org/10.17763/haer.79.4.m6867014157m7071, 2009. 